\title{
Evaluation of Perfluorooctane Surfactants in a Wastewater Treatment System and in a Commercial Surface Protection Product
}

Bryan Boulanger ${ }^{1,2}$, John D. Vargo $^{3}$, Jerald L. Schnoor ${ }^{1}$, and Keri C. Hornbuckle ${ }^{1 *}$

${ }^{1}$ University of Iowa, Department of Civil and Environmental Engineering, SC 4105 Iowa City, IA 52240

${ }^{2}$ Current Address: U.S. Environmental Protection Agency, National Risk Management Research Laboratory, 26 W. Martin Luther King Drive, Cincinnati, OH 45268

${ }^{3}$ University Hygienic Laboratory, 102 Oakdale Campus, Iowa City, IA 52242

* Author to whom correspondence should be sent

email: keri-hornbuckle@uiowa.edu phone: 319.384.0789 Fax: 319.335.566 
Table S1. Perfluorooctane surfactant structures, abbreviations, and names analyzed in this study.

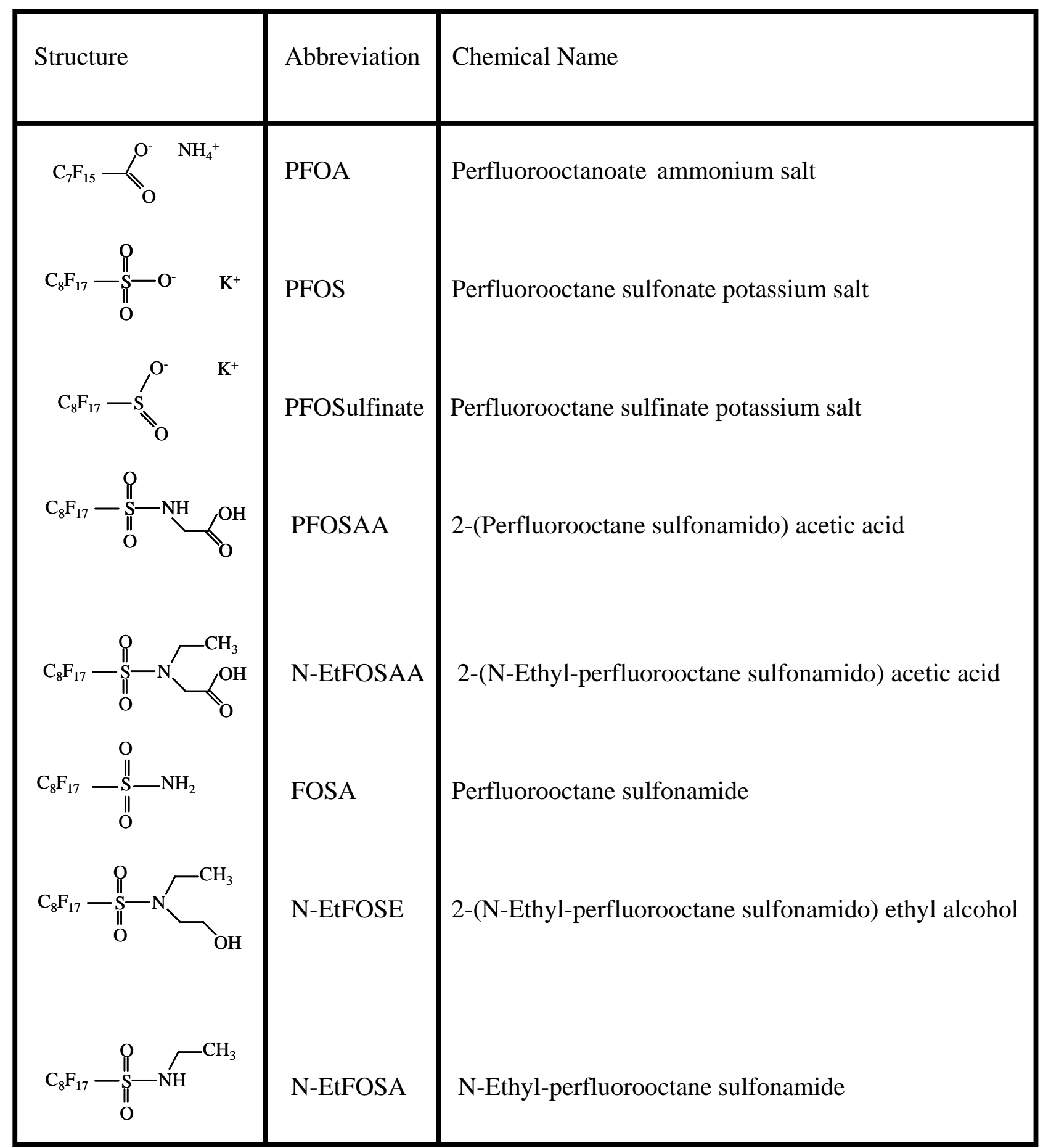




\section{METHODS - EXPANDED}

Chemicals and Standards. Sodium phosphate dihydrate, ammonium chloride, potassium phosphate anhydrous, potassium phosphate monobasic, calcium chloride anhydrous, magnesium sulfate heptahydrate, ferric chloride hexahydrate, potassium chloride, sodium sulfide nonahydrate, ferrous chloride tetrahydrate, magnesium chloride hexahydrate, calcium chloride dehydrate, ammonium phosphate dibasic, cobalt chloride hexahydrate, potassium iodide, sodium hexametaphosphate, manganese chloride tetrahydrate, ammonium metavandate, zinc chloride, sodium molybdate dehydrate, boric acid, nickel chloride hexahydrate, cysteine, sodium bicarbonate, mercuric chloride, nitrobenzene, glacial acetic acid, HPLC grade acetonitrile, HPLC grade methanol, HPLC grade water, and ammonium acetate were purchased through Fisher Scientific.

Description of the South WWTP Layout in Iowa City, IA. Influent enters the plant, is screened, and passes through a grit chamber before entering primary sedimentation basins. Supernantant from primary sedimentation goes through activated sludge treatment before passing into secondary sedimentation basins. The effluent from the clarifiers is then chlorinated, and subsequently dechlorinated, before being discharged to the river. Solids from primary treatment are sent through temperature-phased anaerobic digestion. Following anaerobic digestion, the sludge is dewatered by a belt filter press and land applied.

Wastewater Sample Extraction Details. A vacuum manifold was used to control the flowrate of the wastewater sample through the SPE cartridge. The SPE cartridges were attached to a disposable flow control valve liner and inserted on top of the vacuum extraction chamber. Following assembly of the SPE system, the SPE 
cartridges were washed with $5 \mathrm{ml}$ of methanol followed by $5 \mathrm{ml}$ of HPLC-grade water. The wash solutions were pulled through separately and sequentially under vacuum and the eluent was discarded to waste. For effluent, river water, and field spike samples from these two locations, the entire $1 \mathrm{~L}$ sample volume was pulled through the SPE cartridge under vacuum. For influent samples and spiked influent samples, $0.3 \mathrm{~L}$ were pulled through the cartridges. All aqueous throughput was discarded. After all the sample had passed through the SPE cartridge, the cartridge was rinsed with $5 \mathrm{~mL}$ of $60 / 40(\mathrm{v} / \mathrm{v})$ methanol/HPLC grade water and this rinsate was discarded. Five mL of $100 \%$ methanol was then pulled through the SPE cartridge to elute the retained compounds and was collected in a $30 \mathrm{~mL}$ polycarbonate bottle. From the $5 \mathrm{~mL}$ extracts, two $\mathrm{mL}$ was immediately separated off into another bottle and spiked to a concentration of $100 \mathrm{ng} / \mathrm{mL}$ with a multi-component calibration standard containing all analytes. The remaining 3 $\mathrm{mL}$ was blown down under nitrogen gas to dryness. The samples were then reconstituted in $300 \mu \mathrm{L}$ methanol, placed into an autosampler vial, capped, and analyzed.

Media Preparation. Aerobic mineral medium used in this experiment was prepared on the bench top under flame and contained (grams per liter) $\mathrm{Na}_{2} \mathrm{HPO}_{4}-2 \mathrm{H}_{2} \mathrm{O}$ (0.334), $\mathrm{NH}_{4} \mathrm{Cl}$ (0.005), $\mathrm{K}_{2} \mathrm{HPO}_{4}$ (0.2175), $\mathrm{KH}_{2} \mathrm{PO}_{4}(0.085), \mathrm{CaCl}_{2}$ (0.0275), $\mathrm{MgSO}_{4^{-}}$ $7 \mathrm{H}_{2} 0$ (0.0225), $\mathrm{FeCl}_{3}-6 \mathrm{H}_{2} 0$ (0.00025), and $1 \mathrm{~mL} / \mathrm{L}$ methanol. The aerobic medium was filter sterilized. Aerobic settled sludge solids from the Iowa City South WWTP were added to the sterilized medium under flame to achieve a final concentration of 3\% settled sludge solids by volume in the aerobic bioreactors. The anaerobic mineral medium used in this experiment was prepared in an anaerobic glove box using degassed HPLC grade water and contained (grams per liter) $\mathrm{NH}_{4} \mathrm{Cl}(0.4000), \mathrm{KCl}(0.4000), \mathrm{Na}_{2} \mathrm{~S}-9 \mathrm{H}_{2} \mathrm{O}$ 
(0.3000), $\mathrm{FeCl}_{2}-4 \mathrm{H}_{2} \mathrm{O}(0.0400), \mathrm{MgCl}_{2}-6 \mathrm{H}_{2} \mathrm{O}$ (0.4000), $\mathrm{CaCl}_{2}-2 \mathrm{H}_{2} \mathrm{O}$ (0.0250), $\left(\mathrm{NH}_{4}\right)-$

$2 \mathrm{HPO}_{4}(0.0800), \mathrm{CoCl}_{2}-6 \mathrm{H}_{2} \mathrm{O}(0.0025), \mathrm{KI}(0.0025),\left(\mathrm{NaPO}_{3}\right)_{6}(0.0100), \mathrm{MnCl}_{2}-4 \mathrm{H}_{2} \mathrm{O}$

(0.0005), $\mathrm{NH}_{4} \mathrm{VO}_{3}$ (0.0005), $\mathrm{ZnCl}$ (0.0005), $\mathrm{Na}_{2} \mathrm{MoO}_{4}-2 \mathrm{H}_{2} \mathrm{O}$ (0.0005), $\mathrm{H}_{3} \mathrm{BO}_{3}$ (0.0005), $\mathrm{NiCl}_{2}-6 \mathrm{H}_{2} \mathrm{O}(0.0005)$, and cysteine (0.0100). The media was buffered to neutral $\mathrm{pH}(\mathrm{pH}$ =7) by adding sodium bicarbonate and then filter sterilized. Anaerobic settled sludge solids from the South Iowa City WWTP were added to the sterilized medium to obtain a final concentration of 3\% settled sludge solids by volume in the anaerobic bioreactors.

Nitrobenzene Analysis. One $\mathrm{mL}$ samples from positive anaerobic control were sampled from each bioreactor using a syringe. The one $\mathrm{mL}$ aliquot was then syringe filtered with a $0.45 \mu \mathrm{m}$ filter and sent for analysis. Nitrobenzene was detected using an Agilent 1100 series HPLC/Diode Array Detector system. A $50 \mu$ l extract volume was injected onto a $25 \mathrm{~cm}$ x $4.6 \mathrm{~mm}$ (5 $\mu \mathrm{m}$ ) Suplecosil LC-18 column for chromatographic separation. The mobile phase consisted of 50/50 (v/v) acetonitrile/deionized water buffered with sodium phosphate to $\mathrm{pH}$ 7. The mobile phase flow rate was set at 1 $\mathrm{mL} / \mathrm{min}$. Nitrobenzene was identified and quantified using a diode array detector set at a wavelength of $254 \mathrm{~nm}$ at a retention time of 8.6 minutes. $360 \mathrm{~nm}$ was set as the reference wavelength. 


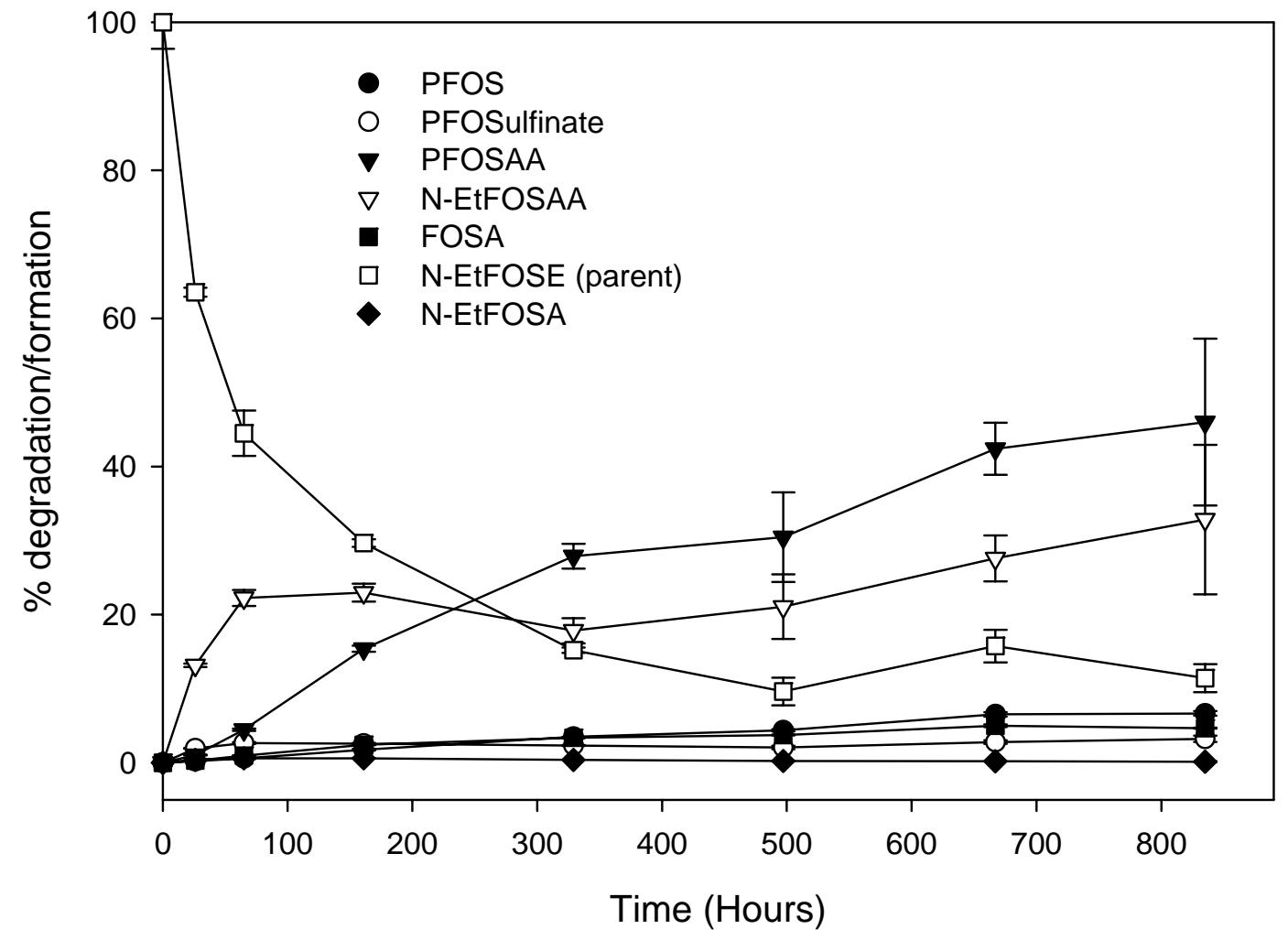

Figure S1. Results of 3M 35 day N-EtFOSE aerobic biotransformation experiments. Data compiled from 3M, 2000 (Docket AR-226). Bioreactors were spiked to $2.380 \mathrm{mg} / \mathrm{L}$ $\mathrm{N}$-EtFOSE at time 0. Error bars represent one standard deviation about the mean of triplicate samples for each time point. N-EtFOSAA and PFOSAA were the two major metabolites formed after 35 days. 

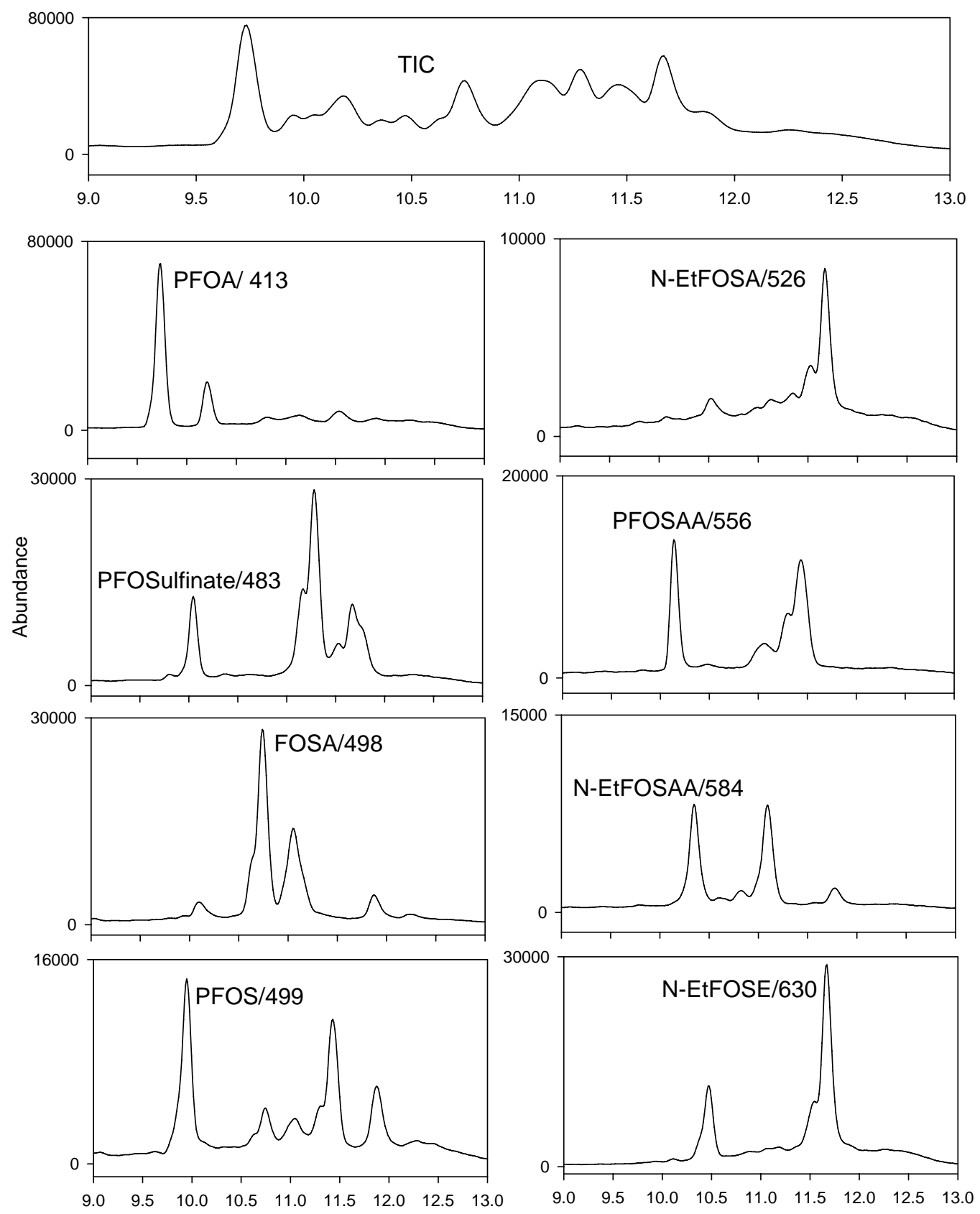

Figure S2. Chromatogram of a 1998 Scotchgard sample analyzed using LC/MS.

Scotchgard was sprayed for approximately 2 seconds into a $30 \mathrm{~mL}$ polycarbonate bottle. The bottle was then filled with $25 \mathrm{~mL}$ of $\mathrm{MeOH}$ and vortex mixed. An aliquot of the undiluted sample solution was analyzed. All analytes were detected in the Scotchgard sample. The total ion chromatogram (TIC) and the chromatogram of each individual signal are shown. The compound name is given along with the $\mathrm{m} / \mathrm{z}$ signal corresponding to the individual chromatogram. The name appears near the peak of the analyzed compound. 
Name: p335-014

Text: Scotchgaurd dil 10E1
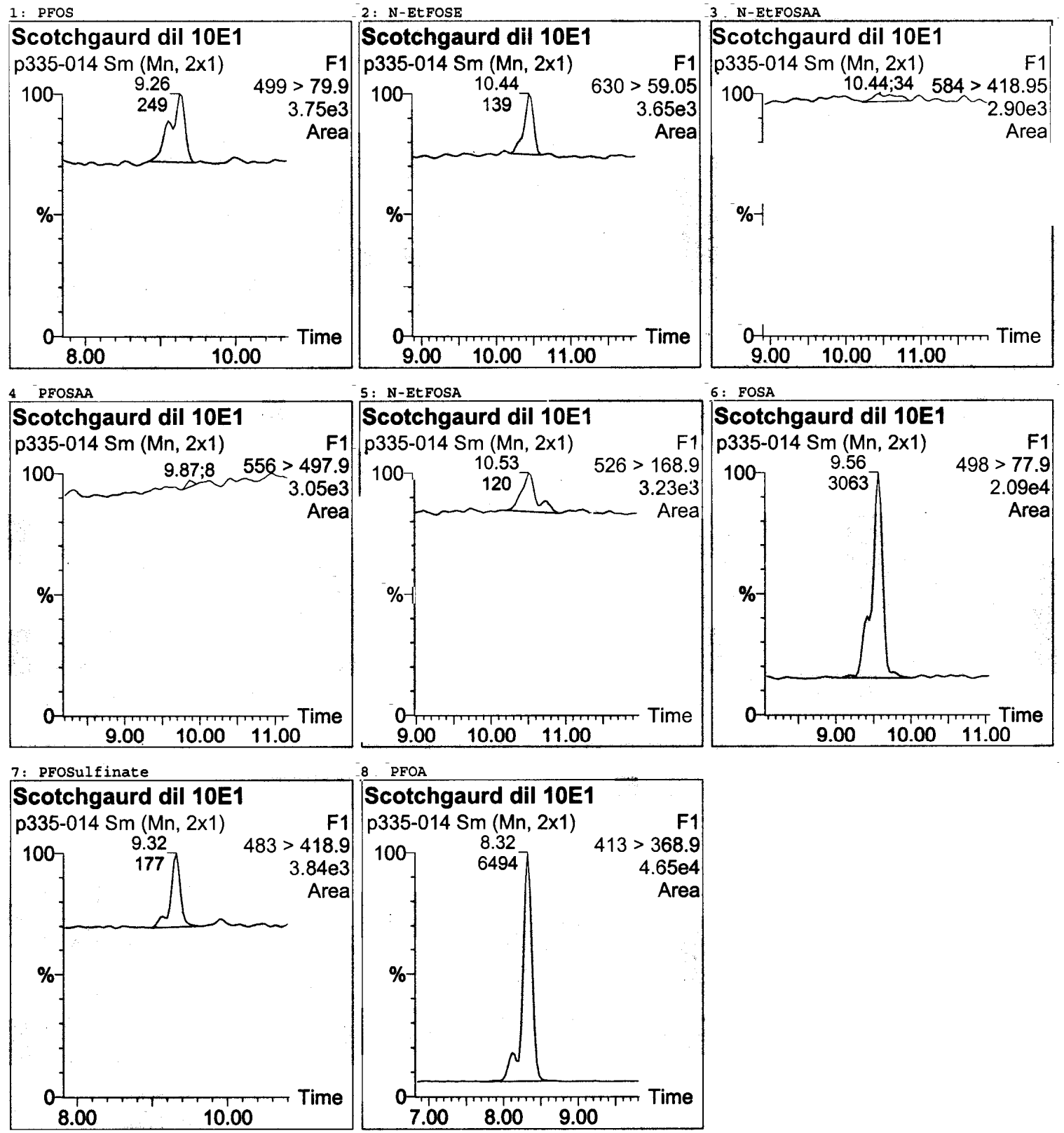

Figure S3. Chromatogram of a 1998 Scotchgard sample analyzed using LC/MS/MS. Scotchgard was sprayed into a $30 \mathrm{~mL}$ polycarbonate bottle. The bottle was then filled with $20 \mathrm{~mL}$ of $\mathrm{MeOH}$ and vortex mixed. A 1:10 dilution of the original sample was analyzed. The chromatograms for each individual compound are shown along with the monitored transition, the area under the curve, and the retention time. These findings support the results presented using LC/MS. 